\title{
Nosocomial Infection Prevention through Universal Precaution in Yogyakarta Muhammadiyah Hospital
}

\author{
Triyani Marwati, Siti Kurnia Widi Hastuti, Lina Handayani, Solikhah, Lafi Munira \\ Faculty of Public Health, Universitas Ahmad Dahlan, Yogyakarta, Indonesia
}

\begin{tabular}{l} 
Article Info \\
\hline Article history: \\
Received Jun 21, 2016 \\
Revised Aug 16, 2016 \\
Accepted Aug 26, 2016 \\
\hline Keyword: \\
Attitude \\
Availibility of facilities \\
Knowledgement \\
Universal precautions
\end{tabular}

Currently attention to nosocomial infections in hospitals in Indonesia is quite high. Given the number of cases of nosocomial infection showed a fairly high. The high incidence of nosocomial infections indicate the quality of health care quality. Nosocomial infections can occur given the hospital is "shed" infectious pathogenic microbes originating mainly from patients with infectious diseases. On the other hand, health workers can also act as sources, in addition to passing the patient's family, medical equipment and hospital environment itself [1].

Prevention of nosocomial through hand washing health workers become very important. The attitude of good nurses in preventing nosocomial infections can improve the behavior of nurses in implementing universal precautions. Nurses knowledge about nosocomial infection affects the nurses who demonstrated against the overall prevention (universal precautions) while the attitude of nurses in an effort to support universal precaution is often shown with indifference and override wash hands after carrying out nursing actions because considers not dirty (not exposed pus or blood) [2].

Nurses are health professionals dealing directly with patients and at most. The frequency of invasive action with the risk of blood and other body fluids is very high. The invasive measures including infusion,

\section{Corresponding Author:}

Siti Kurnia Widi Hastuti

Universitas Ahmad Dahlan,

Prof Soepomo Street, Umbulharjo 55164, Yogyakarta, Indonesia.

Email: kurniawidihastuti@gmail.com

\begin{abstract} implementation of universal precaution program or action asepsis and antisepsis tapping. These actions undertaken by health workers, both nurses gloves, use aseptic liquid, processing of used equipment and waste disposal. 作 (heshammadiyah Yogyakarta area. Design of this research is descriptive discussions. Data analyzed using content analysis. The application of washing action on the water flow, perform hand hygiene, and always nosocomial infections has been well and for prevention need to implement precautions have been good, to the extent responsible. Most hospitals have had the availability of facilities and support the implementation of universal precaution well, and partly still exist limitations in the availability of
\end{abstract}

Copyright (C) 2016 Institute of Advanced Engineering and Science. All rights reserved. 
injection drug, taking the patient's blood, venous catheter placement, and others. Behavioral factors and environmental health personnel work has close links with the application of behavioral compliance prevention of accidents to workers.

The principle of universal precautions (Universal Precautions / UP) is an effective instrument to protect and reduce the incidence of infection in hospital (nosocomial infection) on health workers, patients and the public. Compliance with the implementation of the sub-optimal UP became a major factor in the increase in nosocomial infections in health care centers [3].

Health workers must maintain the health and safety of themselves and others and responsible for implementing the policies established hospital. Health workers are also responsible for using the means provided properly and maintain the facilities that are always ready to use and can be used as long as possible.

The results of the survey on the prevention of infection in health centers or hospital still got some action officer potential increase disease transmission to health care workers, patients served and the public at large, the lack of correct hand washing, use of gloves is not quite right, back closure needle injections are unsafe, disposal of sharp instruments are not safe, decontamination and sterilization techniques are less precise equipment and hygiene practices are not adequate room. The low awareness of health workers in the hospital on the use of Universal Precaution can cause increasing of nosocomial infections so that the prevention of nosocomial infections less than the maximum is a problem faced by hospitals to date.

\section{RESEARCH METHOD}

This research was descriptive qualitative research with case study approach. This research studies the phenomena associated with the application of universal precautions, knowledge of health workers on universal precautions, attitude of health personnel in implementing universal precautions, as well as the availability of facilities and tools supporting the implementation of universal precaution. This study took place in PKU Muhammadiyah Hospital in Yogyakarta. Subjects in this study were nurses and midwives who became the team PPI (Nosocomial Infection Control and Prevention). Data collection techniques using focus group discussions (FGD).

The research instrument used in this study are: 1) FGD guidelines for open discussion with research subjects; 2) Stationery, record sheet, recorders and cameras to support the FGD process with informants (research subjects). The variables used in this study is an overview of universal application of precaution, the health worker knowledge about universal precaution, the attitude of health workers in implementing universal precautions, as well as the availability of facilities and tools supporting the implementation of universal precautions. Analysis of data using semiotic techniquewith content analysis. Checking the validity of the data using data triangulation technique.

\section{RESULTS AND ANALYSIS}

3.1. Overview of the application of universal precautions in PKU Muhammadiyah hospitals on Yogyakarta associated with the prevention of nosocomial infections

Universal Precautions (UP) is vigilance against blood and body fluids that are potentially infectious, both from patients and healthcare workers. Universal precautions should be done by all health professionals to reduce the risk of spreading infection. Here are some excerpts of the interview related to Applied UP in hospitals across Region of Yogyakarta

"Definite before and after the action, wash hands with running water and soap" (PKU Jogja)

"Before and after the action to hand hygiene" (PKU Kota Gede)

"Of yourself trying to always wear personal protective equipment and perform hand hygiene" (PKU Nanggulan)

From the quote above interview, indicating that the health worker is working to implement the UP including hand washing action on the water flow, perform hand hygiene, and always tries to wear PPE. Infected patients ataupunt not, any health care workers should implementation precautions fully in related with all patients.

Evidence-based hand hygiene can prevent transmission of the most important nosocomial pathogens and also keep employees skin healthy. In most clinical situations hygienic disinfection is indicated for hand decontamination on grounds of better afficacy and cutaneous tolerance. Washing with soap and water is necessary only when the hands are visibly soiled, or following disinfection in the case of contamination by spores of bacteria such as $C$. difficile. Compliance could be improved by knowledge of the principal clinical circumstances in wich hand disinfections by health care workers genuinely benefits the patient [4]. Hand 
washing, this is the single most effective hygiene practice for minimizing health care associated infections. Health workers must wash their hands before and after every significant patient contact. Hand washing with hot and cold water supplies, non-touch taps with antisplash devices, supplies of liquid handwash (preferably in non-refillable disposable containers) and disposable paper towels or single-use, clean, cloth towels are recommended to facilitate hand hygiene [5].

The application of universal precautions aimed not only protect workers from exposure to the risk of infection but also protect clients who have a tendency prone to all sorts of infections that might be carried by officers. In addition to prevention efforts undertaken by hospital staff also have preventive measures and promotion in support of the application of universal precautions program, this is in accordance with the following interview excerpt:

"In the neighborhood there were hospital's leaflets, brochures about nosocomial infections, besides officers also remind the patient, the patient's family. There are educational programs for patients and their families, as never before to wash hands properly, the nurse who exemplifies or PPI officer".

"There's our program every new patient education for correct hand washing. There is a checklist, so each new patient is obligated to correct hand washing education to patients and ancestry of patients and visitors ".

"Promotive efforts began from providing a place for hand wash, hand rubs we provide on site or at the points crowded. In addition we also provide leaflets and brochures, and posters."

Efforts should be made to minimize the risk of infection in hospitals and other health care facilities is the prevention and control of infection, ie activities include planning, implementation, development, education and training as well as monitoring and evaluation. Prevention and Infection Control in Hospitals is very important because it illustrates the quality of hospital services [6].

In the application of universal precautions required capabilities as a nurse executive, is back by facilities and infrastructure, as well as Standard Operating Procedures governing the steps universal precautions. This is in accordance with the following interview excerpt:

"Standard Operating Procedures of cross-infection there, especially the linen, nutrition, maintenance, servicing, pharmaceutical, pemulasaran bodies, but it also is a universal standard precautions".

"For the Standard Operating Procedures in relation to the process because of accreditation".

"For the Standard Operating Procedures same inos prevention in the process, but we always applied what we get in in-house training".

From the quote above interview is not all hospitals have SOPs, and is still under construction, but the nurse attempted to apply the skills in accordance with the material given at the time of in-house training. application of washing hands nurses must also be supported by a nurse consciousness itself in protecting themselves and patients from infectious materials as well as awareness in running the correct standart operating procedure (SOP). Hand washing nurses in hospitals, a fundamental behaviors in the prevention of cross infection. Knowledge is a very important element for the formation of a person's actions. Nurses must also have knowledge about the correct hand washing for prevention of nosocomial infections in hospitals so as to improve the quality of service [7]. Hands wash must be done right before and after taking action despite treatment wear gloves or other protective gear for eliminating or reducing microorganisms was on hand so that the spread of the disease can reduced and the environment protected from infection. indications wash hands should be done at the time anticipated the displacement of germs through hand, ie before action which is possible pollution and after action possible pollution [8]. Hands wash is a basic technique that is most important inprevention and control of infection [9].

\subsection{Knowledgement of health workers on universal precautions to prevent the incidence of nosocomial infections in PKU Hospitals in Yogyakarta}

Nurses are highly susceptible to infection transmission, because nurses in providing nursing care to patients will be in direct contact with blood and body fluids. Efforts are being made to reduce the risk of contracting an infection, using universal precautions. Hence the importance of this action is performed, the nurses are required to have adequate knowledge.

Knowledge is the memory of the material that has been studied. Includes the ability to remember the range of material, from specific facts to complete theories. Knowledge is the lowest level of learning outcomes in the cognitive domain. A professional nurse said, if you have the knowledge, skills, and have a 
professional attitude according to the code of professional conduct. Knowledge nurses can continue to increase if the hospital can continue to improve with a variety of training and continuous education for all employees on all aspects of infection prevention [10]. Knowledge about the prevention of nosocomial infections is very important for hospital staff, especially nurses, the ability to prevent the transmission of hospital infections and prevention of infection is the first stage in the delivery of quality services.

"Diseases caused by microorganisms. Infections acquired from the hospital environment, and around the hospital as well as the patient's home in the home environment, and the environment around the patient in addition, cross-infection can be directly transmitted through direct contact with the disease in the hospital'.

"Nosocomial infection is a disease caused by microorganisms with bodily reactions and Infesksi obtained from the hospital environment".

"Nosocomial infections can be transmitted from hospital equipment that is not sterile, officers who do not wear personal protective equipment and do not maintain hand hygiene. Health workers who do not or less attention septic and aseptic technique is infected with the bacteria causing nosocomial infections ".

From the quote above interview nurses knowledge of nosocomial infections has been good, and for prevention need to implement universal precautions by applying one hand higyene and septic and aseptic techniques attention.

Prevention of nosocomial through handwashing health workers become very important. The attitude of good nurses in preventing nosocomial infections can improve the behavior of nurses in implementing universal precautions. Nurses knowledge about nosocomial infection affects the nurses who demonstrated against the overall prevention (universal precautions) while the attitude of nurses in an effort to support universal precaution is often shown with indifference and override wash hands after carrying out nursing actions because considers not dirty (not exposed pus or blood).

Nurses knowledge about the prevention of nosocomial infection and external stimuli that can cause an emotional response to the efforts of nurses universal precaution so that it will increase its participation in the prevention of nosocomial infections. The role of nurses in the prevention of nosocomial infections is very important. Since the average daily $7-8$ hours nurses make contact with the patient so that it can be a major source of exposure / exposure nosocomial infection [10].

Nurses receive training on Personal Protective Equipment has 5.7 times more obedient opportunities to use personal protective equipment when practice. To increase knowledge about the application of the Universal Precaution nurse nurses are given training [11], it is evidenced in the following interview excerpt:

"Training's been done $2 x$ a year (beginning and end of the year) for both medical and non-medical personnel, but it is also our first ever in bina also by Sarjito hospital and once also from jakarta".

"All health workers know nosocomial associated with infection, we have in-house training of PKU Jogja to improve our skills".

"Yes-related skills we have in house training of PKU Jogja but not all health workers receive training related to nosocomial infections".

"Empowerment and conducted periodic training to all employees each year. By socialization about infectious when surveillance".

Knowledge of nurses about $64 \%$ of hand hygiene knowledge is still lacking, knowledge is still lacking due to there are some nurses who have never received education and training on hand hygiene in the past year. Some nurses say never received education and training but forgotten. Another possible reason for the lack of knowledge of hand hygiene for nurses is less exposed to information about hand hygiene and scientific update [12]. Failure to comply with measures such as good hand hygiene, is rarely due to laziness or lack ofcare, but due to barriers preventing effective practice, are caused by: Poor knowledge of the guidelines; A lack of education; Inadequate facilities; Time pressures; Lack of access to hand hygiene agents [13].

\subsection{Attitude of health personnel in the application of universal precaution to prevent the incidence of nosocomial infections in PKU Hospitalsin Yogyakarta}

Attitude is a reaction or response is still closed from someone to a stimulus / object. Attitudes towards an object is feeling supported or siding (favorabel) and feelings of support or non-partisan (unfavorabel). Nurse positive attitude in the form of confidence, ability and inclination to implement 
universal precautions in all patients do not regard the diagnosis of disease or to prevent the transmission of infection through blood and body fluids.

"For example, the most easy to be an agent of transmission is handphone, droplet then there was our officer who exposed or infected then to respond to that as we search, see the infrastructure first and then work environment, eg fentilasi less, the behavior is not a good officer, officers do not wear whereas masks many tuberculosis patients, it could be because there is provided a mask, then this will be a record of PPI".

"Mental attitude we strive least of ourselves already comply or always keep hand hygiene and always wear Personal Protective Equipment".

"Certainly before and after taking action to hand hygiene".

Nurses have reached the level of responsibility, at this level, the individual will be responsible attitude and ready to bear all the risk on everything that has been chosen. Supportive attitude of nurses in universal precautions related to the risk of transmission of infection through blood and body fluids for both patients and nurses.Supportive attitude of nurses in universal precautions related to the risk of transmission of infection through blood and body fluids for both patients and nurses. Such as HIV / AIDS became a global threat and its spread is higher for people living with HIV not show symptoms. This incident is a very important thing done by nurses to reduce the risk of infection by conducting basic universal precautions include: wash hands before and after patient contact, wash hands with running water, wash hands with antiseptic after touching contaminated objects, use personal protective equipment such as gloves, masks aprons when performing actions that cause splashes of blood or body fluids; management of medical equipment such as decontamination apparatus with $0.5 \%$ chlorine for 10 minutes and sterilization, blood contaminated linens stored in leak-proof bag and handle it with gloves; management of sharp instruments such as needles and sharp instruments in place of special waste, not close, break, bend the used needles; waste management such as medical solid waste and non-medical separated. Many factors affect the health workers in the use of personal protective equipment to ensure his safety before contact with a patient and take action. Can be influenced by motivation, behavior, habits and the availability of personal protective equipment [14].

In another study showed incidence of infection experienced a progressive increase, is due to many things, among others due to aseptic practice health workers and visitors still less like the habit of washing hands before treating, caring for holding a patient's use of personal protective equipment such as masks, suits specifically, footwear and gloves for visitors to enter a special room is still lacking, and visiting hours are still often overlooked [15]. Personal protective equipment is a major component of Personal Precaution and its use is commonly used workers especially nurses as standard precautions (standard precautions ) in a nursing action [8]. Another study showed Execution use personal protective equipment in operating rooms DR. Sam Ratulangi Tondano hospital has not been run in accordance with guidelines for infection prevention and control the Health Ministry [14].

\subsection{Availability of tools and facilities to support the implementation of the Universal Precaution to prevent the incidence of nosocomial infections in PKU Muhammadiyah Hospital Yogyakarta}

As part of the implementation of universal precautions for prevention of nosocomial infections in hospitals, support and availability of da facility is important. Factors influence the behavior of health workers to hand washing compliance of individual factors, organization and environment. These three factors are dependence has in influencing compliance in implementing hand hygiene. Factor individuals that affect the knowledge, attitudes, workload, and motivation. Organization factors including procedure, penalties, rewards, support, training and the availability of facilities and infrastructure that support the implementation of hand hygiene. Factor obtained the overall behavior of the nurses were covering the water environment and architecture of the building [16].

Here are the results of the interview excerpts related to the availability of tools and facilities in support of peneapa precautions:

"Our management so support we needed towels, hand wash, hand rubs, masks, tissues, but it is also always available to the operating room sterile gloves, sink, running water and hand soap rubs".

"To the availability of facilities and infrastructure nutuk we make every effort to provide hand wash, hand rubs, but it is also for example we are working with detol and there was a sink and running water". 
"For infrastructure frankly our place is still limited, to hand wash, rubs hands we strive to provide, but for a tool sterilizer we are still using sterile instruments are still modest. we are limited in our place is still minimal budget, but still we allocate ".

Supporting factors include the availability of personal protective equipment in place practices can affect the behavior of the use of personal protective equipment on the respondent. Respondents require supporting equipment is equipment personal protective equipment at the place of practice to be able to use personal protective equipment when to intervene in patients. Although the respondents have a high level of knowledge if it is not supported by the availability of personal protective equipment in the practice of the respondents were unable to use personal protective equipment properly. This is consistent with research one of who explains that $17.8 \%$ respondents failed to use personal protective equipment when practice due to the limited number of personal protective equipment is provided in place of practice [17].

In this study, most hospitals have had the availability and facilities to support the implementation of universal precaution well, and partly still exist limitations in the availability of facilities and support the implementation of universal precaution. It needs special attention from the hospital or local health department given the availability of tools and facilities to support the implementation of universal precautions to prevent the incidence of nosocomial infections is important to be pursued.

In another study showed one obstacles in non-compliance with hand hygiene is the difficulty of access to hand washing or supplies other tools used for hand hygiene. Easy access to inventory the tools to perform hand hygiene, wash hand basin, soap, alcohol jell is very important to make optimal adherence be standardized [16]. The complete facility of hand hygiene in the inpatient unit available with either, Facilities ang provided in each room include: sink, clean running water, soap, anti- microbial and alcohol glycerin to hand rub, Antiseptics availability of liquid soap, hand wash dryer is available in the form of a disposable cloth or tissue [12]. Health care associated infections are associated with morbidity, mortality, and enormous costs to health care facilities, and insurance providers nationwide are denying payment for costs associated with these infections [18].

\section{CONCLUSION}

Health workers have attempted to implement universal precautions included hand washing action on the water flow, pull through hand hygiene, and always tries to wear personal protective equipment. The nurse attempted to apply the skills in accordance with the material given at the time of in-house training. Nurse has reached the level of responsibility, at this level, the individual will be responsible attitude and ready to bear all the risk on everything that has been chosen. Supportive attitude of nurses in universal precautions related to the risk of transmission of infection through blood and body fluids for both patients and nurses. Availability of tools and facilities to support the implementation of universal precaution, most hospitals already have the availability of facilities and support the implementation of universal precaution well, and partly still exist limitations in the availability of facilities and support the implementation of universal precaution.

\section{REFERENCES}

[1] Darmadi, “Nosocomial Infection problems and control,” Salemba Medika, Jakarta, 2008.

[2] A. A. Hidayat, "Introduction to Basic Human needs,” Salemba Medika, Jakarta, 2006.

[3] Ministry of Health of the Republic of Indonesia, "Guidelines for Universal Precautions in Health Care Facilities," Jakarta, 2003.

[4] G. Kampf, H. Loffler, P. Gasmeier, "Hand Hygiene for the Prevention of Nosocomial Infections," Journal of Deutsches Arzteblatt International, vol/issue: 106(40), pp. 649-55, 2009.

[5] Y. Mehta, A. Gupta, S. Todi, et al., "Guidelines for prevention of hospital acquired infections,” Indian Journal Critical Care Medicine, vol/issue: 18(3), pp. 149-163, 2014.

[6] L. Salawati, “Nosocomial Infection Control in the Intensive Care Unit Lounge Hospital,” Jurnal Kedokteran Syiah Kuala, vol/issue: 12(1), pp. 47-52, 2012.

[7] N. Fauzia, A. Ansyori, T. Haryanto, "Hand Hygiene Compliance at Standard Operating Room Nurses in Inpatient Hospital,” Jurnal Kedokteran Brawijaya, vol/issue: 8(1), pp. 95-97, 2014.

[8] Ministry of Health of the Republic of Indonesia, "Guidelines for Prevention and Infection Control in Hospitals and Health Care Facilities,” Jakarta, 2008.

[9] P. Potter, "Fundamental Concepts of Nursing Process and Practice,” EGC, Jakarta, 2005.

[10] M. U. D. Putra, "Knowledge and Attitude Levels Relationship With Behavior Using Personal Protective Equipment At Profession Student Faculty of Nursing,” Thesis, University of Indonesia, Jakarta, 2012.

[11] Ministry of Health of the Republic of Indonesia, "Standard Equipment of Nursing and midwifery in Health," Jakarta, 2001. 
[12] E. Ernawati, R. A. Tri, S. Wiyanto, “Aplication of nurse’s hand hygiene in hospital's Inpatient Units,” Jurnal Kedokteran Brawijaya, vol/issue: 28(1), pp. 89-93, 2014.

[13] J. B. Ball, “The Control and Prevention Hospital-acquired Infections,” Journal Nursing Time, vol/issue: 100(29), pp. 28-29, 2004.

[14] A. P. Masloman, G. D. Kandow, Ch. R. Tilaar, "Implementation Analysis, Prevention, and Control of Infection, in the Operating Room Hospital Dr. Sam Ratulangi Tondano,” Junal Ilmu Kesehatan Masyarakat Universitas Syamratulangi, vol/issue: 5(2), pp. 238-249, 2015.

[15] R. Nugraheni, W. S. Suhartono, "Nosocomial infections in hospitals Setjonegoro Kabupaen Wonosobo,” Jurnal Media Kesehatan Masyarakat Indonesia, vol/issue: 11(1), pp. 94-100, 2012.

[16] D. Pittet, "Improving Adherence to hand hygiene Practice: A Multidisciplinary Approach,” Journal Emerging Infectious Diseases, vol/issue: 7(2), pp. 234-240, 2011.

[17] T. M. M. Maja, "Precaution use by occupational health nursing students during clinical placement," Adelaide, Tswane University of Technology, 2009.

[18] Eannie P. C., Linda H. A., Douglas. M. S., Evan S. W., "Nurse staffing, burnout, and health careeassociated infection,” American Journal of Infection Control, vol. 40, pp. 486-490, 2012. 